\title{
Characterisation and analysis of thioredoxin peroxidase as a potential antigen for the serodiagnosis of sarcoptic mange in rabbits by dot-ELISA
}

\author{
Runhui Zhang ${ }^{1}$, Wanpeng Zheng ${ }^{1}$ X Xuhang Wu', Quwu Jise', Yongjun Ren², Xiang Nong ${ }^{1}$, Xiaobin Gu', \\ Shuxian Wang ${ }^{1}$, Xuerong Peng ${ }^{3}$, Songjia Lai ${ }^{4}$ and Guangyou Yang ${ }^{1 *}$
}

\begin{abstract}
Background: Scabies caused by Sarcoptes scabiei is a widespread but a neglected tropical zoonosis. In this study, we characterised a S. scabiei thioredoxin peroxidase (SsTPx) and evaluated a recombinant SsTPx as a diagnostic antigen in rabbits.

Methods: The open reading frame of the gene encoding SsTPX-2 was amplified and the recombinant protein was expressed in Escherichia coli cells and purified. SsTPx was localized in mite tissue by immunolocalisation using the purified recombinant protein. Serodiagnosis assays were carried out in 203 New Zealand White rabbit serum samples by dot-ELISA.

Result: The open reading frame (489 bp) of the gene encodes an $18.11 \mathrm{kDa}$ protein, which showed highly homology to that of Psoroptes cuniculi (98.77\% identity) and belongs to the 2-Cys family of peroxiredoxins. SsTPx was mainly distributed in muscle tissues of mites, integument of the epidermis and the anterior end of $\mathrm{S}$. scabiei. Although SsTPx cross-reactivity with psoroptic mites was observed, the SsTPx dot-ELISA showed excellent diagnostic ability, with 95.3\% sensitivity and 93.8\% specificity in mange-infected and uninfected groups.
\end{abstract}

Conclusions: This study showed that the purified SsTPx is a highly sensitive antigen for the diagnosis of mange infection by dot-ELISA. This technique is a rapid and convenient method that can be used worldwide for the clinical diagnosis of sarcoptic mange in rabbits, and is especially useful in developing regions.

Keywords: Sarcoptes scabiei, Thioredoxin peroxidase, Immunolocalisation, Dot-ELISA, Serodiagnosis

\section{Background}

Sarcoptes scabiei is an ectoparastic mite infecting both humans and animals. Scabies has been reported as a widespread but a neglected tropical disease that is highly contagious in conditions of overcrowding, poverty and poor hygiene [1-3]. More than 100 species of mammals such as companion pets, livestock and wildlife are generally affected, causing severe mortality resulting from the uncontrolled spread of Sarcoptes [4] with significant impacts in terms of welfare and economic losses [5-7].

\footnotetext{
*Correspondence: guangyou1963@yahoo.com.cn.

'Department of Parasitology, College of Veterinary Medicine, Sichuan Agricultural University, Ya'an 625014, China

Full list of author information is available at the end of the article
}

Scabies typically causes pruritus which is frequently more intense at night, and skin inflammation, inducing papular or vesicular lesions related to the burrowing mites and their products [3,7]. Papules and vesicles often develop into excoriations, eczematisations, secondary infections and scabs [8]. However, scabies can be difficult to identify because of severe scratching, inflammation or secondary bacterial infection resulting in misdiagnosis [9]. The pathognomonic evidence for the diagnosis of scabies is the burrow. However, these burrows tend to be invisible to the naked eye so that it should be diagnosed by skilled doctors using advanced techniques such as dermoscopy [10]. A clinical algorithm relevant to itching and lesions, in addition to host biomarkers, are 
used to differentiate between the stages of scabies and mange [11,12]. An interesting study has demonstrated the use of trained disease-detector dogs that had an efficient capability to detect sarcoptic mange in wildlife [13]. In addition, several reports have described the serodiagnostic methods for scabies and mange. For example, an antigen that is homologous to the house dust mite is a candidate antigen for the diagnosis of sarcoptic mange by immunoscreening $[14,15]$. S. scabiei extracts have been used to detect sarcoptic mange infections using enzymelinked immunosorbent assays (ELISAs) [16-18], but some assays lack appropriate levels of specificity and sensitivity [19]. Thus, the development of efficient methods for the correct identification of scabies and sarcoptic mange is required to reduce the spread of this infection.

Thioredoxin peroxidase (TPx) is a member of peroxiredoxin family (Prx), which is an antioxidant that functions as a peroxidase only when coupled to a sulfhydryl reducing system [20]. Prx has been crucially implicated in protecting organisms from the potentially damaging effects of reactive oxygen species (ROS) and host-activated leukocytes in many parasites [21]. Opisthorchis viverrini TPx contributes to the protection of the parasite against damage induced by ROS produced during inflammation [22]. Moreover, thioredoxin peroxidases are widely used in methods for the diagnosis of parasitic diseases. For example, purified recombinant TPx of E. granulosus was used to screen sera from mice and patients with severe hydatid infections [23]. Furthermore, TPx is considered to be a candidate antigen for the detection of Schistosoma japonicum and Fasciola gigantica infections in water buffalo [24,25].

The dot-enzyme-linked immunosorbent assay (dotELISA) is a simple, rapid and reliable method for screening large number of serum samples [26]. The use of extracts of Sarcoptes mites as capture antigens in dot-ELISAs has been established for the diagnosis of sarcoptic mange in rabbits [27]. The aim of this study was to develop a dot-ELISA assay for the serodiagnosis of sarcoptic mange using recombinant TPx protein and to perform the characterisation and immunolocalisation of thioredoxin peroxidase in Sarcoptes scabiei (SsTPx).

\section{Methods}

\section{Mites and samples}

Sarcoptic mites (adults, nymphs and larvae) were collected from rabbits and stored at $-70^{\circ} \mathrm{C}$ prior to RNA extraction. The mites were unfed before the start of the experiment to avoid any contamination of the host RNA and proteins. Serum samples were collected from naïve adult New Zealand White rabbits as well as those that had been naturally and experimentally infected with different levels of mites. All animals were handled in strict accordance with the animal protection laws of the
People's Republic of China (a draft of an animal protection law in China was released on September 18, 2009). All procedures were carried out in strict accordance with the Guide for the Care and Use of Laboratory Animals by the Animal Ethics Committee of Sichuan Agricultural University (Ya'an, China) (Approval No. 2011-028).

\section{Cloning, expression and purification of recombinant SsTpx}

Total RNA was extracted using a commercial kit (Waston, Shanghai, China) and cDNA was transcribed using RevertAi ${ }^{\mathrm{ma}}$ First Strand cDNA Synthesis Kit (Fermentas) according to the manufacturers' protocols and stored at $-70^{\circ} \mathrm{C}$. The sequence encoding an open reading frame (ORF) of SsTPx was amplified from the $S$. scabiei EST database [28] and Psoroptes ovis thioredoxin peroxidase gene using the primers 5'-ccgcaattcATGG CAGTGAAGAATCCG-3' and 5'-cccaagcttTCAAACTG ATCGGCCGAC-3' (Invitrogen), which incorporated EcoRI and HindIII restriction sites, respectively. The PCR products were digested and gel-purified. The cDNA was subcloned into the bacterial expression vector pET32a (+) (Novagen, Germany) and used to transform BL21 (DE3) Escherichia coli cells (Novagen). E.coli cells were cultivated in LB medium containing $50 \mu \mathrm{g} / \mathrm{mL}$ ampicillin at $37^{\circ} \mathrm{C}$ overnight until the $\mathrm{OD}_{600 \mathrm{~nm}}$ value reached 1.0. Isopropyl-beta-d-thiogalactopyranoside (IPTG) was then added at the final concentration of $1 \mathrm{mM}$ and cells were incubated for a further $4 \mathrm{~h}$ at $37^{\circ} \mathrm{C}$ to induce recombinant SsTPx expression. The purity of the expressed protein was measured as previously described [29].

\section{Sequence analysis}

The presence of a signal peptide was detected using SignalP-4.1 at the Center of Biological Sequence Analysis (http://www.cbs.dtu.dk/services/SignalP-4.1/), and cellular localization was predicted using TMHMM (http://www. cbs.dtu.dk/services/TMHMM/). The molecular weight of the predicted protein was calculated using Compute $\mathrm{pI} /$ Mw (http://web.expasy.org/protparam/).

\section{Western blot analysis}

Recombinant SsTPx was separated by SDS-PAGE and transferred onto PVDF membranes (Millipore, Germany) for $1 \mathrm{~h}$ in an electrophoretic transfer cell (Bio-Rad, USA). The membrane was blocked with 5\% skimmed milk in TBST ( $40 \mathrm{mM}$ Tris- $\mathrm{HCl}, 0.5 \mathrm{M} \mathrm{NaCl}$, 0.1 Tween-20, $\mathrm{pH}$ 7.4) for $2 \mathrm{~h}$ at room temperature. Membranes were then incubated with rabbit antiserum (diluted 1:200 (v/v) in 1\% skimmed milk in TBST) overnight at $4^{\circ} \mathrm{C}$. After washing with TBST $(3 \times 5 \mathrm{~min})$ the membrane was incubated with horseradish peroxidase (HRP)-conjugated goat anti-rabbit antibody for $1 \mathrm{~h}$. After the membrane was washed again with TBST $(3 \times 5$ 

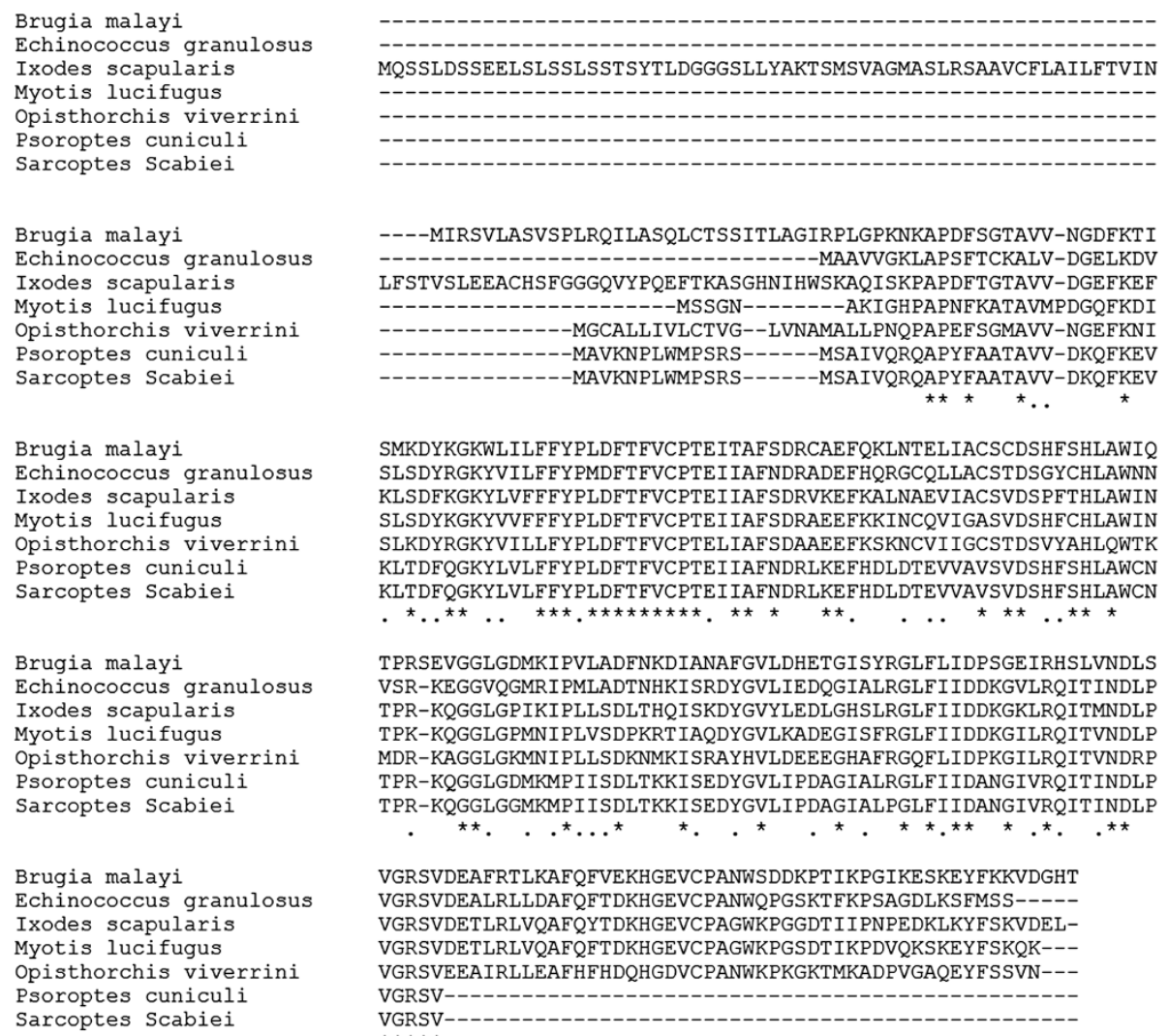

----MIRSVLASVSPLRQILASQLCTSSITLAGIRPLGPKNKAPDFSGTAVV-NGDFKTI ------------MAAVVGKLAPSFTCKALV-DGELKDV LFSTVSLEEACHSFGGGQVYPQEFTKASGHNIHWSKAQISKPAPDFTGTAVV-DGEFKEF ------------MGCALLIVLCTVG--LVNAMALLPNQPAPEFSGMAVV-NGEFKNI -----------MAVKNPLWMPSRS-----MSAIVQRQAPYFAATAVV-DKQFKEV $\star \star \star \star *$.

SMKDYKGKWLILFFYPLDFTFVCPTEITAFSDRCAEFQKLNTELIACSCDSHFSHLAWIQ SLSDYRGKYVILFFYPMDFTFVCPTEIIAFNDRADEFHORGCOLLACSTDSGYCHLAWNN KLSDFKGKYLVFFFYPLDFTFVCPTEIIAFSDRVKEFKALNAEVIACSVDSPFTHLAWIN SLSDYKGKYVVFFFYPLDFTFVCPTEI IAFSDRAEEFKKINCQVIGASVDSHFCHLAWIN SLSDYKGKYVVFFFYPLDFTFVCPTEI IAFSDRAEEFKKINCQVIGASVDSHFCHLAWIN
SLKDYRGKYVILLFYPLDFTFVCPTELIAFSDAAEEFKSKNCVI IGCSTDSVYAHLQWTK KLTDFQGKYLVLFFYPLDFTFVCPTEI IAFNDRLKEFHDLDTEVVAVSVDSHFSHLAWCN KLTDFQGKYLVLFFYPLDFTFVCPTEI IAFNDRLKEFHDLDTEVVAVSVDSHFSHLAWCN

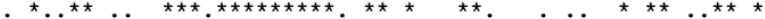

TPRSEVGGLGDMKI PVLADFNKDIANAFGVLDHETGISYRGLFLIDPSGEIRHSLVNDLS VSR-KEGGVQGMRI PMLADTNHKISRDYGVLIEDQGIALRGLF I IDDKGVLRQITINDLP TPR-KQGGLGPIKI I LLSDLTHQISKDYGVYLEDLGHSLRGLFI IDDKGKLRQITMNDLP TPK-KQGGLGPMNI PLVSDPKRT IAQDYGVLKADEGISFRGLFIIDDKGILRQITVNDLP MDR-KAGGLGKMNI PLLSDKNMKISRAYHVLDEEEGHAFRGQFLIDPKGILRQITVNDRP TPR-KQGGLGDMKMPI ISDLTKKISEDYGVLI PDAGIALRGLF I IDANGIVRQIT INDLP TPR-KQGGLGGMKMPI ISDLTKKISEDYGVLIPDAGIALPGLFI IDANGIVRQIT INDLP

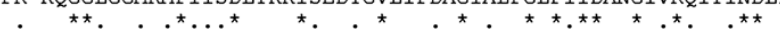

VGRSVDEAFRTLKAFQFVEKHGEVCPANWSDDKPTIKPGIKESKEYFKKVDGHT VGRSVDEALRLLDAFQFTDKHGEVCPANWQPGSKTFKPSAGDLKSFMSS----VGRSVDETLRLVQAFQYTDKHGEVCPAGWKPGGDTI IPNPEDKLKYFSKVDELVGRSVDETLRLVQAFQFTDKHGEVCPAGWKPGSDTIKPDVQKSKEYFSKOK--VGRSVEFATRULAFH VGRSV---------

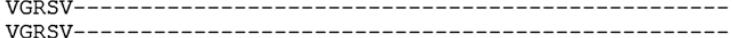

VGRSV

Figure 1 Amino acid sequence alignment of thioredoxin peroxidase from Sarcoptes Scabiei and other species. GenBank accession numbers: Brugia malayi, AAC23701.1; Echinococcus granulosus, AAL84833.1; Ixodes scapularis, XP_002415327.1; Myotis lucifugus, AAT79401.1; Opisthorchis viverrini, ACB13822.1; Psoroptes cuniculi, KF241278.

min), protein signals were detected using diaminobenzidine (DAB) reagent (Tiangen, China) following the manufacturer's instructions.

\section{Immunohistochemistry}

In order to perform immunolocalisation studies of mite sections, antiserum against SsTPx was raised in rabbits using standard procedures [30]. Mites were fixed in 1\% molten agarose, embedded in paraffin wax after solidification of the molten agarose and cut into sections (5 $\mu \mathrm{m})$ with a microtome. The sections were dewaxed, rehydrated, treated to inactivate endogenous peroxidase and incubated in 25\% normal goat serum in TBS for 15 min. Tissue sections were then incubated with specific rabbit anti-SsTPx antibodies (diluted 1:1000 (v/v) in TBS) overnight at $4^{\circ} \mathrm{C}$. After washing three times with TBS the sections were then incubated with horseradish peroxidase (HRP)-conjugated goat anti-rabbit IgG (AMRESCO, Texas, USA) diluted 1:200 for $1 \mathrm{~h}$. Sections were rinsed with TBS then immunoreactivity was detected using the EnVisionTM+ System, HRP (DAB) (DAKO, Glostrup, Denmark). The sections were counterstained with hematoxylin and dehydrated and cleared

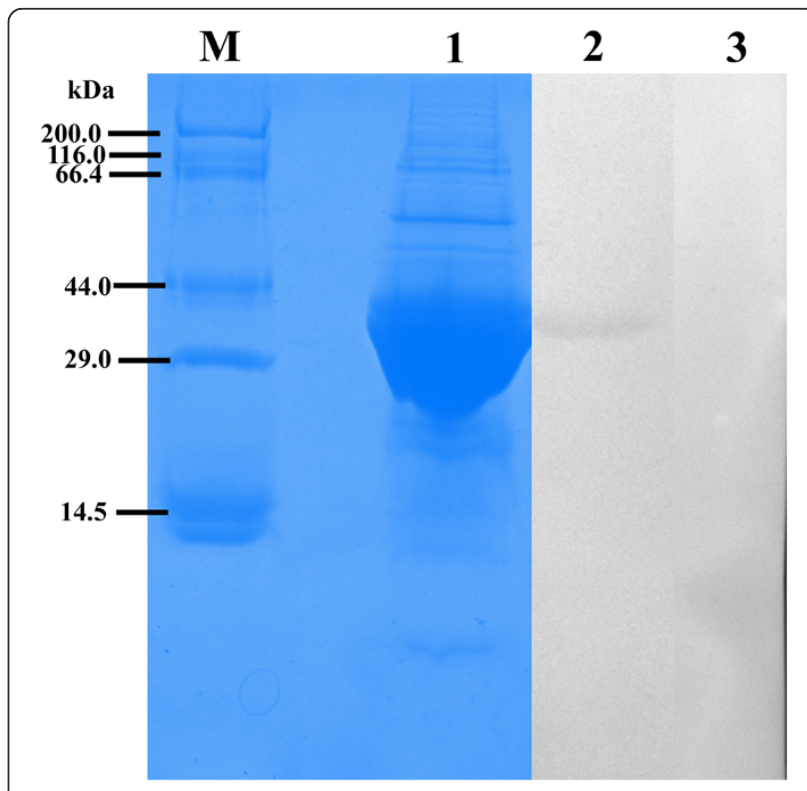

Figure 2 Western blot analysis of the recombinant SsTPx. M, protein molecular weight markers; Lane 1, purified recombinant proteins; Lane 2, Western blot detection with S. scabiei infected rabbit antisera; Lane 3, Western blot detection with naïve serum. 

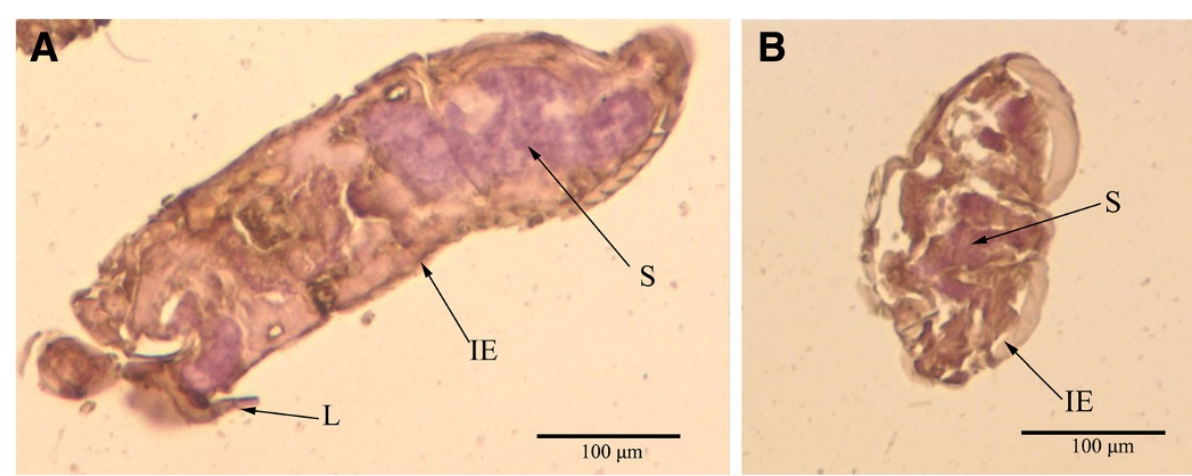

Figure 3 Immunohistochemistry of SsTPx in sections of S. scabiei. (A, B) Staining with SsTPx antiserum as the primary antibody. The EnVision $\mathrm{TM}+$ System-HRP(DAB) (DAKO) was used, according to the manufacturer's instructions for detection of the rabbit antibodies. L, legs; $\mathrm{S}$, stomach blocks; IE, epidermal integument.

in xylene. Finally, sections were mounted and viewed with a microscope. Negative controls were prepared using naïve rabbit serum instead of specific antibodies.

\section{Dot-ELISA}

The concentration of coating protein and serum dilution was optimized for use in the SsTPx dot-ELISA. Antigen $(2 \mu \mathrm{g} / \mathrm{mL}, 6 \mu \mathrm{g} / \mathrm{mL}$ and $24 \mu \mathrm{g} / \mathrm{mL})$ was dotted onto the nitrocellulose membrane (NCM), which were hydrated with phosphate-buffered saline (PBS; $0.1 \mathrm{M}, \mathrm{pH} 7.4$ ), for $1 \mathrm{~h}$ at room temperature. The membrane was then dried at $37^{\circ} \mathrm{C}$ for $2 \mathrm{~h}$ and cut into strips (approximately $0.5 \times 3$ $\mathrm{cm}$ ), each containing $1 \mu \mathrm{L}$ antigen. The strips were blocked with PBST containing 5\% skimmed milk for 30 min and washed with PBST (PBS, 0.3\% Tween-20) three times. Sera (diluted 1:200) were then added and incubated at $37^{\circ} \mathrm{C}$ for $1 \mathrm{~h}$ before being washed with PBST three times. Each strip was then incubated with HRPconjugated goat anti-rabbit IgG diluted 1:1000 in PBS. Dot-ELISA was developed with the EnVisionTM+
System, HRP (DAB). Serum samples infested with Psoroptes cuniculi $(\mathrm{n}=12)$, Eimeria stiedae $(\mathrm{n}=6)$ and Taenia pisiformis $(\mathrm{n}=6)$ were used as controls for the detection of cross-reactivity. All the dot strips were kept at $4^{\circ} \mathrm{C}$. Eighty-five serum samples from infected rabbits were tested and 94 negative controls were treated with naïve rabbit serum. The stability of the strips was also evaluated by detection of infected serum and negative serum samples $(\mathrm{n}=6$ each) three times.

Results were read on the basis of color variation in the PVDF membranes: brown dots indicated a positive result, while no dots indicated a negative result. Test sensitivity was calculated as: sensitivity = ELISA positive/ true positive $\times 100 \%$. Test specificity was calculated as: specificity $=$ ELISA negative/true negative $\times 100 \%$ [31]

\section{Evaluation and statistical analysis}

Evaluation of dot-ELISAs was based on a previously reported method [32] with the following modification: two independent observers read all the dot-ELISA strips

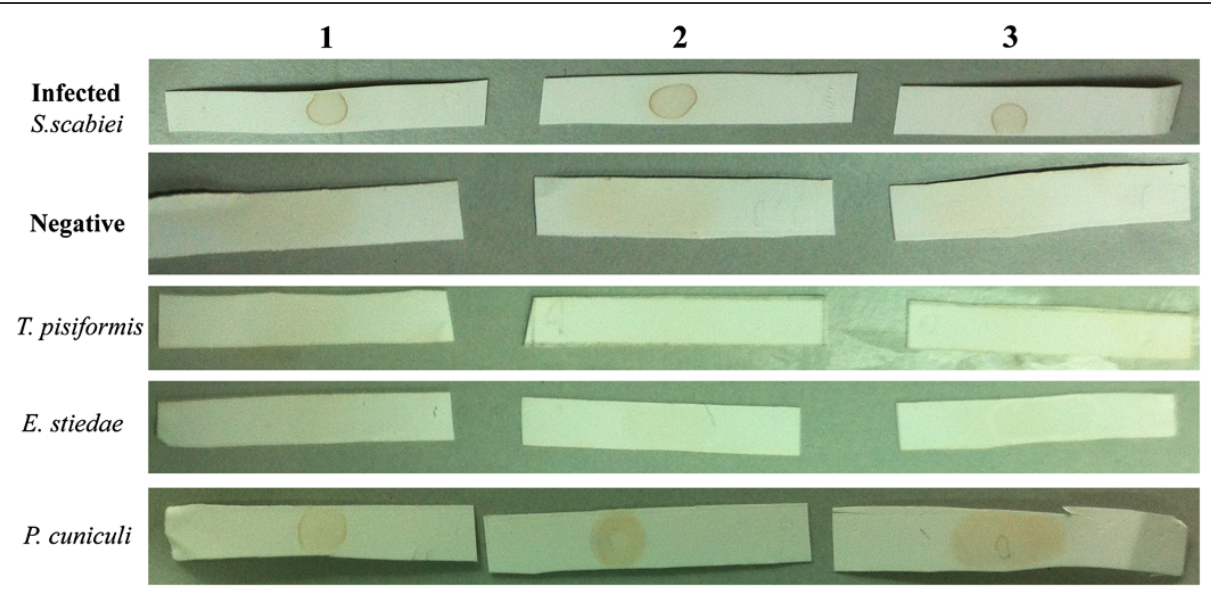

Figure 4 Dot-ELISA showing reactivity of infected group and uninfected groups using three concentrations of recombinant SsTPx protein as a capture antigen. Lane 1,2 $\mathrm{g} / \mathrm{mL}$ protein; Lane $2,6 \mu \mathrm{g} / \mathrm{mL}$ protein; Lane 3, $24 \mathrm{\mu g} / \mathrm{mL}$ protein. 
Table 1 Detection of recombinant SsTPx in infected S. scabiei serum, negative serum and controls by dot-ELISA

\begin{tabular}{|c|c|c|c|c|c|c|c|c|}
\hline \multirow[t]{2}{*}{ Groups $(n=203)$} & \multicolumn{2}{|c|}{ Observer 1 number } & \multirow{2}{*}{$\begin{array}{c}\text { Sensitivity } \\
\text { or specificity }\end{array}$} & \multicolumn{2}{|c|}{ Observer 2 number } & \multirow{2}{*}{$\begin{array}{c}\text { Sensitivity } \\
\text { or specificity }\end{array}$} & \multirow{2}{*}{$\begin{array}{l}\text { Kappa } \\
\text { index* }\end{array}$} & \multirow{2}{*}{$\begin{array}{l}\text { Proportion } \\
\text { agreement } \\
\text { (PA) }\end{array}$} \\
\hline & + & - & & + & - & & & \\
\hline S. scabiei infected- $(\mathrm{n}=85)$ & 81 & 4 & $95.3 \%$ & 80 & 5 & $94.1 \%$ & 0.882 & $98 \%$ \\
\hline Total uninfected $(\mathrm{n}=118)$ & 7 & 111 & $94.1 \%$ & 8 & 110 & $93.2 \%$ & 0.928 & $99 \%$ \\
\hline Negative $(n=94)$ & 0 & 94 & $100 \%$ & 0 & 94 & $100 \%$ & 1.0 & $100 \%$ \\
\hline E.stiedae $(\mathrm{n}=6)$ & 0 & 6 & $100 \%$ & 0 & 6 & $100 \%$ & 1.0 & $100 \%$ \\
\hline T.pisiformis $(n=6)$ & 0 & 6 & $100 \%$ & 0 & 6 & $100 \%$ & 1.0 & $100 \%$ \\
\hline P. cuniculi $(n=12)$ & 7 & 5 & $68.3 \%$ & 8 & 4 & $66.7 \%$ & 0.823 & $91 \%$ \\
\hline
\end{tabular}

*Strength of agreement: $\mathrm{K}$ index $<0$, poor; $0-0.20$, slight; $0.21-0.4$, fair; $0.41-0.6$, moderate; $0.61-0.80$, substantial; $0.81-1.0$; almost perfect.

on the same day. Observer 1 read all of the strips again two days later to evaluate observer variability. The kappa index $(\mathrm{K})$ and $\mathrm{P}$ values were used to evaluate assay results (http://graphpad.com/quickcalcs/kappa1/).

\section{Results}

\section{Sequence alignment and expression}

We cloned an ORF of 489 bp encoding a 163 amino acid protein (GeneBank accession number: KC693033). The protein was predicted to have a molecular weight of $18.11 \mathrm{kDa}, \mathrm{a}$ pI of 6.82 , and weak hydrophobicity. No signal peptides or transmembrane domains were found in this protein. An alignment of SsTPx is shown in Figure 1. SsTPx was found to be highly homologous to that of Psoroptes ovis (98.77\% identity) and Psoroptes cuniculi (98.77\% identity) and exhibited homology to that of other parasites such as Myotis lucifugus, Echinococcus granulosus, Ixodes scapularis thioredoxin peroxidase (45.93\%, 44.66\% and 35.74\% identity, respectively). Recombinant SsTPx was significantly expressed as an insoluble protein with a molecular weight of approximately $40 \mathrm{kDa}$ (Figure 2). An additional peptide (20 $\mathrm{kDa})$ was expressed from the pET-32a (+) vector.

\section{Western blot analysis}

Western blot analysis showed that this recombinant protein reacted with $S$. scabiei infected rabbit antisera. Immunoreactivity was not observed when negative rabbit serum was used (Figure 2).

\section{Immunohistochemistry}

Obvious staining was widespread in mite muscle tissue and the epidermal integument. This protein was mainly located in the anterior end of S. scabiei (Figure 3). No staining was detected with pre-immune serum (data not shown).

\section{Dot-ELISA}

The optimal dilution of the serum and controls for use in dot-ELISA assays was 1:200 and the optimal concentration of the recombinant SsTPx antigen was $2 \mu \mathrm{g} / \mathrm{mL}$ (data not shown). A total of 203 rabbit sera were evaluated. Most experimentally or naturally infected S. scabiei sera (average 81/85, 95.3\% sensitivity) showed positive reactivity in dot-ELISAs, while most S. scabiei-negative sera (average 111/118, 93.8\% specificity) showed no reaction with SsTPx. In the control groups, SsTPx showed no cross-reaction with E. stiedae $(0 / 6)$ and $T$. pisiformis (0/6). Cross-reactivity was observed with $P$. cuniculiinfected (7-8/12) serum although the definition of the dots was less clear that those of the $S$. scabiei infected group (Figure 4). No obvious variation was observed among the results for the three time-points tested indicating the stability of the membrane-bound antigen.

The evaluations made by the two observers are shown in Table 1. Among the first evaluations of the S. scabiei infected group, Observers 1 and 2 reported 95.3\% and 94.1\% sensitivity, respectively, with a corresponding $\mathrm{K}$ index of 0.882 (98\% proportion agreement (PA), $P<0.01)$. In the negative and control groups (E. stiedae and T. pisiformis), specificity ranged from $98.9 \%$ to $100 \%$ with $\mathrm{K}$ concordance indexes of $0.794,1.0$ and 1.0 $(P<0.01)$, and PA of $98 \%, 100 \%$ and $100 \%$, respectively. Specificity of the P. cuniculi group was $68.3 \%$ (Observer 1 ) and $66.7 \%$ (Observer 2 ) with a $K$ concordance index of $0.823(P<0.01)$ and PA of $91 \%$. The PA between the first and second readings made by Observer 1 was 98\% $(\mathrm{K}=0.851, P<0.01)$ in the $S$. scabiei infected group (Table 2).

Table 2 Kappa index and PA between the first and second readings of observer 1

\begin{tabular}{|c|c|c|c|c|c|}
\hline Groups $(n=203)$ & S.scabiei infected $(n=85)$ & Negative $(n=94)$ & E.stiedae $(\mathrm{n}=6)$ & T. pisiformis $(\mathrm{n}=6)$ & P. cuniculi $(\mathrm{n}=12)$ \\
\hline Kappa index & 0.851 & 1.0 & 1.0 & 1.0 & 0.833 \\
\hline Proportion agreement(PA) & $98 \%$ & $100 \%$ & $100 \%$ & $100 \%$ & $91 \%$ \\
\hline
\end{tabular}




\section{Discussion}

In the present study, we have described the characterisation and localization of a peroxiredoxin (Prx) from $S$. scabiei, and evaluated its use as a diagnosis antigen. The existence of two conserved cysteine residues at positions 61 and 97 demonstrates that this protein belongs to the 2-Cys peroxiredoxin family [33]. 2-Cys TPx in yeast has been shown to have peroxidase activity and intermolecular disulfide linkage [34]. TPx is characterised as an antioxidant enzyme from parasites including Echinococcus granulosus, Fasciola hepatica, Schistosoma mansoni and Onchocerca volvulus [35]. The amino acid sequence of SsTPx shows high homology with TPx from P. ovis. Furthermore, immunohistochemical analysis showed that SsTPx was located in the anterior end of mite, which is similar to the location of TPx from P. ovis [36]. Also, the detection of the protein in the epidermal integument and muscles close to the epidermis implicates SsTPx in the protection of S. scabiei against oxidative damage.

Many studies have identified TPx as a candidate antigen for the diagnosis of parasitic infections. Purified TPx has been used as capture antigens for serodiagnosis of Fasciola gigantica infection, as well as Schistosoma japonicum infection in buffalo [24]. Data have also indicated that the use of specific recombinant TPx from Echinococcus granulosus as a capture antigen increased the diagnostic sensitivity of an ELISA for the detection of hydatid infection [37]. In addition, a previous study in our laboratory showed that whole mite extracts can be effectively used as diagnostic antigens by dot-ELISA [27]. ELISA using S.scabiei extracts has been used for the diagnosis of sarcoptes mange in animals $[16,19]$. However, this approach is limited by the lack of an in vitro culture system for mites and and the host crossreactivity [5]. In comparison to standard plate ELISAs, the dot-ELISA is a simple and accurate method that does not require any specialized equipment. Therefore, this study aimed to evaluate the potential use of recombinant antigens in the diagnosis of sarcoptic mange in rabbits by dot-ELISA.

In our study, sera from rabbits with common parasitic infections were selected as control groups for the detection of cross-reactivity. The lower specificity observed in the $P$. cuniculi group may indicate cross-reactivity with $P$. cuniculi infection. Infection of rabbits with the zooparasite $P$. cuniculi causes serious pruritus and scabs which can completely cover the external ear canal and the internal surfaces of the pinna [38]. However, psoroptic mites, which are significantly larger than scabies mites, are readily visible to the naked eye or otoscope. Moreover, psoroptic mite infection and mange affect different areas of the body in rabbits. Consequently, we considered that the SsTPx antigen was suitable for the detection of sarcoptic mange in rabbits.
Recently, S.cabiei recombinant antigens have considered as potential diagnostic tools. A previous study showed that quantification of recombinant allergenspecific IgE levels by DELFIA is highly sensitive method for the diagnosis of scabies infections. This allergen showed excellent diagnostic capability with $100 \%$ sensitivity and $93.75 \%$ specificity [39]. Recombinant ELISA assay indicated it was a potentially complementary tool for diagnosing swine mange affected by human derived S.scabiei [40]. In our study, most infected sera were recognized by recombinant SsTPx and no reactivity was observed with negative serum. The assay showed high sensitivity (95.3\%) and specificity (93.8\%) in three evaluations by two independent observers. Another report showed $92 \%$ sensitivity and $96 \%$ specificity in serodiagnosis of canine sarcoptic mange by ELISA [41]. The K index revealed predominant concordance between the evaluations of the infected and total uninfected groups made by the two observers as well as that observed between the first and second readings of Observer 1. Thus, the high sensitivity and specificity of the dot-ELISA developed in this study indicate that recombinant SsTPx is a suitable diagnostic antigen. This rapid and convenient diagnostic technique will be of critical importance in the world especially in the developing world where advanced medical instrumentation is unavailable.

\section{Conclusion}

In conclusion, we have characterised a peroxiredoxin from Sarcoptes scabiei and analyzed its diagnostic value. Our results demonstrate localization of the protein in muscle tissues and the anterior end of S. scabiei. The dot-ELISA was developed using purified SsTPx as a capture antigen and exhibited high diagnostic efficiency. This technique represents a rapid and convenient method for the clinical diagnosis of sarcoptic mange in rabbits worldwide especially for the developing regions.

\section{Competing interests}

The authors declare that they have no competing interests.

\section{Authors' contributions}

RZ participated in the design of the study, manuscript writing and performed the statistical analysis; WZ and JQ participated in experiment and discussion; XW carried out the molecular genetic studies; YR and XN participated in the collection of mites samples and data; $X G$ prepared figures and tables; SW participated in sequence alignment, XP prepared figures and helped to draft the manuscript; SL provided the support of experiment animals and serum samples; GY participated in the design of study and have given final approval of the version; All authors read and approved the final manuscript.

\section{Acknowledgements}

This study was supported by a grant from the Program for Changjiang Scholars and Innovative Research Team in University (PCSIRT) (Grant no. IRT0848).

\section{Author details}

${ }^{1}$ Department of Parasitology, College of Veterinary Medicine, Sichuan Agricultural University, Ya'an 625014, China. ${ }^{2}$ Sichuan Academy of Animal 
Husbandry Sciences, Chengdu 610066, China. ${ }^{3}$ Department of Chemistry, College of Life and Basic Science, Sichuan Agricultural University, Ya'an 625014, China. ${ }^{4}$ College of Animal Science and Technology, Sichuan Agricultural University, Ya'an 625014, China.

Received: 11 March 2013 Accepted: 17 July 2013

Published: 22 July 2013

\section{References}

1. Payne L, Fitchett JR: Bringing neglected tropical diseases into the spotlight. Trends Parasitol 2010, 26(9):421.

2. Mounsey KE, McCarthy JS, Walton SF: Scratching the itch: new tools to advance understanding of scabies. Trends Parasitol 2012, 29(1):35-42

3. McCarthy J, Kemp DJ, Walton S, Currie B: Scabies: more than just an irritation. Postarad Med J 2004, 80(945):382-387.

4. Pence D, Ueckermann E: Sarcoptic manage in wildlife. Rev Sci Tech 2002, 21(2):385.

5. Walton SF, Holt DC, Currie BJ, Kemp DJ: Scabies: new future for a neglected disease. Adv Parasitol 2004, 57:309-376.

6. Alasaad S, Walton S, Rossi L, Bornstein S, Abu-Madi M, Soriguer RC Fitzgerald S, Zhu XQ, Zimmermann W, Ugbomoiko US: Sarcoptes-World Molecular Network (Sarcoptes-WMN): integrating research on scabies. Int J Infect Dis 2011, 15(5):e294-e297.

7. Hay R, Steer A, Engelman D, Walton S: Scabies in the developing world-its prevalence, complications, and management. Clin Microbiol Infect 2012, 18(4):313-323.

8. Heukelbach J, Feldmeier H: Scabies. Lancet 2006, 367(9524):1767-1774.

9. Gould D: Prevention, control and treatment of scabies. Nursing standard (Royal College of Nursing (Great Britain): 1987 2010, 25(9):42.

10. Prins C, Stucki L, French L, Saurat JH, Braun R: Dermoscopy for the in vivo Detection of Sarcoptes scabiei. Dermatology 2004, 208(3):241-243.

11. Mahé A, Faye O, N'Diaye HT, Ly F, Konare H, Keita S, Traoré A, Hay R: Definition of an algorithm for the management of common skin diseases at primary health care level in sub-Saharan Africa. Trans $R$ Soc Trop Med Hyg 2005, 99(1):39-47.

12. Rahman MM, Lecchi C, Fraquelli C, Sartorelli P, Ceciliani F: Acute phase protein response in Alpine ibex with sarcoptic mange. Vet Parasitol 2010, 168(3):293-298.

13. Alasaad S, Permunian R, Gakuya F, Mutinda M, Soriquer RC, Rossi L: Sarcoptic-mange detector dogs used to identify infected animals during outbreaks in wildlife. BMC Vet Res 2012, 8(1):110

14. Albrecht J, Bigby M: Testing a test: critical appraisal of tests for diagnosing scabies. Arch Dermatol 2011, 147(4):494.

15. Kuhn C, Lucius R, Matthes H, Meusel G, Reich B, Kalinna B: Characterisation of recombinant immunoreactive antigens of the scab mite Sarcoptes scabiei. Vet Parasitol 2008, 153(3):329-337

16. Bornstein S, Frössling J, Näslund K, Zakrisson G, Mörner T: Evaluation of a serological test (indirect ELISA) for the diagnosis of sarcoptic mange in red foxes (Vulpes vulpes). Vet Dermatol 2006, 17(6):411-416.

17. Sarasa M, Rambozzi L, Rossi L, Meneguz PG, Serrano E, Granados J-E, González FJ, Fandos P, Soriguer RC, Gonzalez G: Sarcoptes scabiei: Specific immune response to sarcoptic mange in the Iberian ibex Capra pyrenaica depends on previous exposure and sex. Exp Parasitol 2010, 124(3):265-271.

18. Rambozzi L, Menzano A, Lavin S, Rossi L: Biotin-avidin amplified ELISA for detection of antibodies to Sarcoptes scabiei in chamois (Rupicapra spp.). Vet Res 2004, 35(6):701-708

19. Löwenstein $M$, Kahlbacher $H$, Peschke $R$ : On the substantial variation in serological responses in pigs to Sarcoptes scabiei var. suis using different commercially available indirect enzyme-linked immunosorbent assays. Parasitol Res 2004, 94(1):24-30.

20. Zhang P, Liu B, Seo MS, Rhee SG, Obeid LM: Thioredoxin peroxidase is a novel inhibitor of apoptosis with a mechanism distinct from that of BCl-2. J Biol Chem 1997, 272(49):30615-30618.

21. Berggren MI, Husbeck B, Samulitis B, Baker AF, Gallegos A, Powis G: Thioredoxin peroxidase-1 (peroxiredoxin-1) is increased in thioredoxin-1 transfected cells and results in enhanced protection against apoptosis caused by hydrogen peroxide but not by other agents including dexamethasone, etoposide, and doxorubicin. Arch Biochem Biophys 2001, 392(1):103-109.
22. Suttiprapa S, Loukas A, Laha T, Wongkham S, Kaewkes S, Gaze S, Brindley PJ, Sripa B: Characterization of the antioxidant enzyme, thioredoxin peroxidase, from the carcinogenic human liver fluke, Opisthorchis viverrini. Mol Biochem Parasitol 2008, 160(2):116-122.

23. Zhang W, McManus DP: Recent advances in the immunology and diagnosis of echinococcosis. FEMS Immunol Med Microbiol 2006, 47(1):24-41.

24. Angeles JMM, Goto Y, Kirinoki M, Asada M, Leonardo LR, Rivera PT, Villacorte EA Inoue N, Chigusa Y, Kawazu S: Utilization of ELISA Using Thioredoxin Peroxidase1 and Tandem Repeat Proteins for Diagnosis of Schistosoma japonicum Infection among Water Buffaloes. PLOS Negl Trop Dis 2012, 6(8):e1800.

25. Zhang W, Rogniaux H, Huang W, Chauvin A, Moreau E: Analysis of thioredoxin peroxidase as a promising antigen for diagnosis of Fasciola gigantica infection: A preliminary study. Parasitol Int 2011, 60(2):206-208.

26. Manoharan S, Parthiban M, Prabhakar T, Ravikumar G, Koteeswaran A, Chandran N, Rajavelu G: Rapid serological profiling by an immunocombbased dot-enzyme-linked immunosorbent test for three major poultry diseases. Vet Res Commun 2004, 28(4):339-346.

27. Hao GY, Yang GY, Gu XB: Application and estabilishing of a method of detecting antibodies of Sarcoptes Scabiei in rabbits by dot-ELISA. Progress Vet Med 2009, 30(4):8-13.

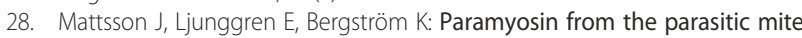
Sarcoptes scabiei: cDNA cloning and heterologous expression. Parasitology 2001, 122(05):555-562.

29. Chen WJ, Niu DS, Zhang XY, Chen ML, Cui H, Wei WJ, Wen BH, Chen XR: Recombinant 56-kilodalton major outer membrane protein antigen of Orientia tsutsugamushi Shanxi and its antigenicity. Infect Immun 2003, 71(8):4772-4779.

30. Liddell S, Knox D: Extracellular and cytoplasmic Cu/Zn superoxide dismutases from Haemonchus contortus. Parasitology 1998, 116(4):383-394.

31. Varghese A, Raina O, Nagar G, Garg R, Banerjee P, Maharana B, Kollannur JD: Development of cathepsin-L cysteine proteinase based Dot-enzyme -linked immunosorbent assay for the diagnosis of Fasciola gigantica infection in buffaloes. Vet Parasitol 2012, 183(3-4):382

32. Piña R, Gutiérrez AH, Gilman RH, Rueda D, Sifuentes $C$, Flores M, Sheen $P$, Rodriguez S, Garćá HH, Zimic M: A dot-ELISA using a partially purified cathepsin-L-like protein fraction from Taenia solium cysticerci for the diagnosis of human neurocysticercosis. Ann Trop Med Parasitol 2011, 105(4):311.

33. McGonigle S, Dalton J, James E: Peroxidoxins: a new antioxidant family. Parasitol Today 1998, 14(4):139-145.

34. Chae HZ, Chung SJ, Rhee SG: Thioredoxin-dependent peroxide reductase from yeast. J Biol Chem 1994, 269(44):27670-27678.

35. Chiumiento L, Bruschi F: Enzymatic antioxidant systems in helminth parasites. Parasitol Res 2009, 105(3):593-603

36. McNair C, Nisbet A, Billingsley P, Knox D: Molecular characterization, expression and localization of a peroxiredoxin from the sheep scab mite, Psoroptes ovis. Parasitology 2009, 136(4):453.

37. Margutti $P$, Ortona E, Delunardo F, Tagliani A, Profumo E, Riganò R, Buttari B, Teggi A, Siracusano A: Thioredoxin peroxidase from Echinococcus granulosus: a candidate to extend the antigenic panel for the immunodiagnosis of human cystic echinococcosis. Diagn Microbiol Infect Dis 2008, 60(3):279-285.

38. Bates P: Inter-and intra-specific variation within the genus Psoroptes (Acari: Psoroptidae). Vet Parasitol 1999, 83(3):201-217.

39. Jayaraj R, Hales B, Viberg L, Pizzuto S, Holt D, Rolland JM, O'Hehir RE, Currie BJ, Walton SF: A diagnostic test for scabies: IgE specificity for a recombinant allergen of Sarcoptes scabiei. Diagn Microbiol Infect Dis 2011, 71(4):403-407

40. Casais R, Goyena E, Martínez-Carrasco C, Ybáñez R, Vega F, Ramis G, Prieto J, Berriatua E: Variable performance of a human derived Sarcoptes scabiei recombinant antigen ELISA in swine mange diagnosis. Vet Parasitol 2013. In press.

41. Bornstein S, Thebo P, Zakrisson G: Evaluation of an enzyme-linked immunosorbent assay (ELISA) for the serological diagnosis of canine sarcoptic mange. Vet Dermatol 2008, 7(1):21-28.

doi:10.1186/1471-2334-13-336

Cite this article as: Zhang et al:: Characterisation and analysis of thioredoxin peroxidase as a potential antigen for the serodiagnosis of sarcoptic mange in rabbits by dot-ELISA. BMC Infectious Diseases 2013 13:336 